\title{
Pseudo-Conditionals AND CAUSAl Assertibles IN STOIC LOGIC
}

\author{
MiguEL LÓPEZ-ASTORGA
}

\begin{abstract}
The Stoics not only analyzed sentences showing to be clear conditionals. They also reviewed other kinds of sentences related to the conditional that are not exactly conditionals, for example, the pseudo-conditionals and the causal assertibles. In this paper, I try to argue that the Stoic account of such sentences reveals that certain problems that contemporary cognitive science is concerned with, such as the ways the different relationships between clauses in a sentence can be expressed or the pragmatic phenomenon of the conditional perfection, were already considered by the Stoics, and that they even did deep studies of those problems. To do that, I resort to the semantic analysis of models usually made by the mental models theory, and use it as a methodological tool.
\end{abstract}

Keywords: Causal assertible; conditional; mental models theory; pseudo-conditional; Stoic logic.

\section{Introduction}

It is evident that current cognitive science has certain problems to solve today. Some of them, which will be addressed in this paper, refer to the conditional, the ways certain relationships between concepts or states can be expressed in natural language, and the pragmatic phenomena that can happen when we use a sentence with a structure similar to that of the conditional. However, my aim here is not to clarify problems such as those ones. My basic goal is to try to show that ancient philosophers already noted and dealt with such problems, giving even detailed accounts of them. In particular, I will argue that the Stoics were aware of the mentioned difficulties and seriously tried to study and understand them.

To do that, I will resort, as a methodological strategy, to the procedures and semantic analyses that are to be found in works authored by the proponents of the mental models theory (e.g. Johnson-Laird 2006; 2010; 2012 2015; Johnson-Laird and Byrne 2002; Johnson-Laird, Khemlani, and Goodwin 2015; Khemlani, Orenes, and Johnson-Laird 2014). This does not necessarily mean that I will assume all of the general theses of that theory in this paper. My only intention is to use its habitual methodological procedures to better account for certain arguments offered by the Stoics. In fact, using the semantic analyses of the mental models theory as a methodological instrument is nothing new. That has been done in papers such as, e.g., those of López-Astorga (2014a; 2015a), who also has already resorted to that theory to

Principia 20(3): 417-426 (2016).

Published by NEL — Epistemology and Logic Research Group, Federal University of Santa Catarina (UFSC), Brazil. 
explain ancient logic issues (López-Astorga 2015b) and even other particular problems in Stoic logic (López-Astorga (2016). Thus, in a similar way, I will take the basic arguments that the followers of the mental models theory have provided to the conditional in order to analyze two special types of sentences identified by the Stoics: the 'pseudo-conditional' and the 'causal assertible' (these are the names given to these types by Barnes, Bobzien, and Mignucci 2008, p.109).

In this way, this paper has two relevant sections, each of them devoted to one of those types. In each section, I will present the description of that particular type of sentences given by the Stoics, and comment on the difficulties or problems to which that type is linked. Likewise, the two sections will include an account of how those types of sentences can be understood from the mental models theory and what they imply under this framework. However, it is obvious that, before starting with the first of those two sections, it seems to be appropriate to explain the general approach of the mental models theory, at least its part related to the themes that will be reviewed here.

\section{The mental models theory and its view of the conditionals}

The mental models theory is not a philosophical or logical theory. It is a psychological framework intending to explain human reasoning. If the literature on cognitive science is reviewed, it can be noted that this theory is supported by very strong empirical evidence based on experiments, and that it is most likely the reasoning approach that can account for more cognitive phenomena.

Nevertheless, as said, my goal here is not to argue in favor of the mental models theory. I only wish to use its methodological tools to offer a clearer and more accurate explanation of the problems that the Stoics addressed when they studied the pseudoconditional and the causal assertible. Thus, given that the theory deals with very different aspects and fields of human cognition related to reasoning, I point out that what will be described below is only a minimal part of its general framework, and that I will only focus on the points of the theory that are interesting for the aims of this paper.

Maybe the essential thesis of the mental models theory is that it claims that the reasoning processes are basically semantic processes. Individuals do not make inferences applying formal rules such as those provided by Gentzen (1934; 1935). They only consider and assess semantic possibilities that represent the possible scenarios to which the sentences refer. So, given a conditional such as 'if $x$ then $y$ ', the theory states that its semantic possibilities are the following three scenarios, where 'stands for denial:

Principia 20(3): 417-426 (2016). 


$$
\begin{array}{ccc}
{[A]} & x & y \\
{[B]} & -x & y \\
{[C]} & -x & -y
\end{array}
$$

In this way, $[A]$ represents a scenario in which both what the antecedent $(x)$ expresses and what the consequent $(y)$ expresses happen. On the other hand, $[B]$ refers to a situation in which only y happens. And finally $[C]$ represents a possibility in which neither $x$ nor $y$ occur.

A very important point of the theory, but not to us here, is that $[A],[B]$, and $[C]$ are the 'Fully Explicit Models' of the conditional, i.e., all of the models or possibilities of the conditional that people can identify if they make enough effort. Usually, people only easily note $[A]$. $[B]$ and $[C]$ require more reflection. Nonetheless, perhaps another thesis of the theory is more important here. It states that certain mechanisms of modulation have an influence on the human mind as well. And that concept, the one of modulation, is more relevant for the goals of this paper. Modulation is "the process in the construction of models in which content, context, and knowledge can prevent the construction of a model and can add information to a model" (Johnson-Laird et al. 2015, p.202). A good example that can show how modulation works is this one:

If you want to eat, then there is a restaurant two blocks from here.

This example represents one of the possible interpretations that the mental models theory assigns to the conditional. In particular, it is named 'relevance' by JohnsonLaird and Byrne (2002, p.663). But what is interesting now is that its semantic possibilities are not $[A],[B]$, and $[C]$. Its actual possibilities are the following:

[I] You want to eat There is a restaurant two blocks from here

$[I I]$ You do not want to eat There is a restaurant two blocks from here

It is clear that [I] corresponds to $[A]$ and [II] to $[B]$. However, as it can be checked, $[C]$ has disappeared, and the reason is obvious: it is not possible to consider a scenario in which the restaurant mentioned in the sentence does not exist $(-x)$, since the context suggests that it does, and that it is two blocks from here.

This example allows us to see that modulation, by virtue of the meaning of the sentences, can remove possibilities. And this point is important because, according to the proponents of the mental models theory, a biconditional seems to be a conditional whose Fully Explicit Models set does not include [B]. So, it can be thought that modulation can transform a conditional into a biconditional since the meanings of the clauses (the antecedent and the consequent) can show that $[B]$ is impossible.

As it can be noted below, taking this idea into account can be very useful to clearly understand what the Stoics stated about the causal assertible. Nevertheless, maybe 
it is enough for now what has been explained with regard to the mental models theory. Hence I only repeat that the theory deals with many other aspects of human reasoning (including those linked to other logical operators), indicate that its main theses and arguments are to be easily found in the literature, and start with the analysis of the Stoic account of one of the kinds of sentences mentioned above: the pseudo-conditional.

\section{The pseudo-conditional and its semantic possibilities}

It is true that the real Stoic interpretation of the conditional has been studied in details. Testimonies and arguments such as, e.g., on the one hand, those of Sextus Empiricus (Pyrrhoniae Hypotyposes 8, 113, and 8, 245), Bocheński (1963, p.89), López-Astorga (2015b, p.10), Mates (1953, p.44), and O'Toole and Jennings (2004, p.479), and, on the other hand, those of Cicero (De Fato 12), Diogenes Laërtius (Vitae Philosophorum 7, 73), Sextus Empiricus (Pyrrhoniae Hypotyposes 2, 111), Barnes et al. (2008, p.107), Gould (1970, p.76), López-Astorga (2015c, p.9), Mueller (1978, p.20), and O'Toole and Jennings (2004, p.492) have clearly shown two facts. One of them is that the interpretation of the conditional assumed by standard logic today, i.e., the material interpretation, comes from Philo of Megara. And the other one, which is very important, is that the Stoic criterion of the conditional was different. That criterion, which is usually attributed to Chrysippus of Soli (see, e.g., O'Toole and Jennings 2004, p.479), referred to a connection between the two clauses, which caused the negation of the then-clause to be incompatible with the if-clause.

This reveals that there is no doubt that the Stoics (and some of their contemporaries) took into account a relevant problem with which cognitive scientists are still concerned at present. That problem is that a sentence with the structure if ... then ...' can be interpreted in different ways (as previously indicated, Johnson-Laird and Byrne's paper in 2002 considers this issue). Nevertheless, a lot of research has been done on this theme and my intention here is not to address it. This paper mainly focuses on another problem that current cognitive science needs to clarify as well: there are also other sentences with other structures (in which neither 'if' nor 'then' appear) that seem to provide a conditional relationship (or at least a relationship akin to the one that the conditional provides). One kind of such sentences is the type

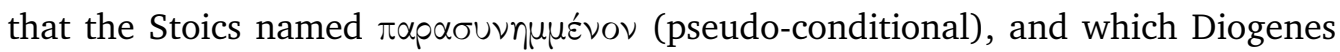
Laërtius attributes to Crinis (Vitae Philosophorum 7, 71).

Indeed, the pseudo-conditional appears in principle to refer to a relationship such

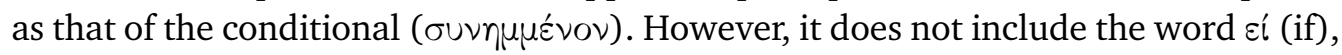

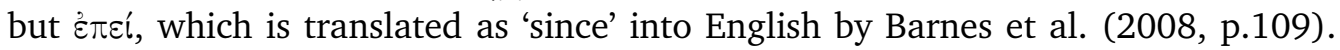
Thus, the sentences of this kind would be expressed in this way: 'since $x, y$ '. And the

Principia 20(3): 417-426 (2016). 
link of this structure to the conditional can seem to be obvious if we think about the possibilities that, according to the mental models theory, could a priori correspond to it. True, $[A],[B]$, and $[C]$ appear to be the initially appropriate combinations of possibilities for a sentence such as 'since $x, y$ '. And this is so because it can be thought that the only combination that is not allowed by that sentence is that in which $x$ is true and $y$ is false. 'Since $x, y$ ' means that, if $x$ happens, $y$ must happen too. Nevertheless, when $x$ does not happen, it can admit both that $y$ happens and that $y$ does not happen. What cannot be allowed is, as said, that $x$ happens and $y$ does not happen.

Hence, the questions are which is the difference between the sentences with $\varepsilon$ e $\pi$ í

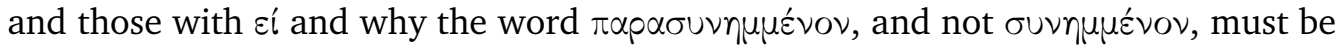
used to refer to the former. The answers to these questions provided by the Stoics are not hard to understand. They claimed that the pseudo-conditional with 'since' had to fulfill necessarily two conditions. "(i) the 'consequent' must follow (from) the 'antecedent' and (ii) the 'antecedent' must be true" (Barnes et al. 2008, p.109; quotes and parentheses in text). These two requirements come from Diogenes Laërtius (Vitae Philosophorum 7, 74) too, but maybe the second one is the most important condition, since it is the one that really enables to differentiate a $\sigma u \nu \eta \mu \mu \varepsilon v o \nu$ from a $\pi \alpha p \alpha \sigma u-$

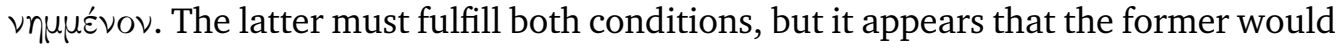
only have to comply with (i). The reason for this is that, while it can be thought that the Stoic interpretation of the conditional requiring a connection between the two clauses mentioned above forces to that (i) is also a characteristic of the sentences with 'if,' (ii) provides an additional condition that requires the antecedent to be true at the moment of speaking. Thus, a sentence such as, 'since you are eating, you are moving your mouth' would only be correct if it is true that you are eating at the moment of saying the sentence. If this is not so, it is better to state the sentence with 'if,' i.e., it is better to state that 'if you are eating, then you are moving your mouth.'

However, this in turn reveals a very relevant difference between the conditional and the pseudo-conditional. If the first clause of the latter must be true, $[B]$ and $[C]$ have to be eliminated because they are impossible ( $x$ is false in them). So, in the Stoic view, the difference between the conditional and the pseudo-conditional (or, if preferred, between the sentences with 'if' and the sentences with 'since') is clear: the former refers to $[A],[B]$, and $[C]$, but only $[A]$ corresponds to the latter. In this way, it can be stated that the word $\varepsilon \pi \varepsilon i$ had a particular role for the Stoic logicians. It linked concepts, facts, or ideas that could also be linked by عí. However, not all of

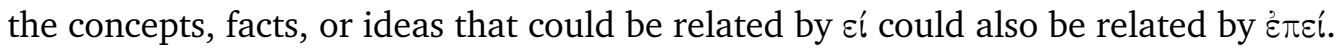
This last word was reserved for scenarios in which the first clause was in fact true.

As mentioned by Barnes et al. (2008, p.109; footnote 85), several writers, including, for example, Burnyeat (1982, pp.218-224), have studied in detail the pseudoconditional. Nevertheless, beyond those studies and their conclusions, what is im- 
portant here is that the Stoic analysis of the $\pi \alpha p \alpha \sigma u v \eta \mu \mu \varepsilon$ vov proves that, as argued, the Stoics were aware of the problem that there are sentences akin to the conditional that do not include the term 'if'. And, as also shown, they tried to detect what distinguished some of them from the conditional. Nonetheless, the pseudo-conditionals were not the only sentences with such characteristics that they researched. The next section deals with the other case: that of the causal assertible.

\section{The causal assertible and its semantic possibilities}

A second kind of sentence similar to the conditional but without the term 'if' is the one that, based on the Greek word aitı $\widetilde{\omega} \delta \varepsilon \varsigma$, as previously said, Barnes et al. (2008, p.109) named 'causal assertible.' The term that replaces 'if' here is $\delta$ เótl (translated by Barnes et al. 2008, p.109, as 'because'). So, this kind is about sentences with the structure 'because $x, y$ '.

However, this type of sentence raises a new difficulty. Now, it is necessary not only to distinguish the causal assertible from the real conditional, but also the causal assertible from the pseudo-conditional. In principle, this task should not be hard, since Diogenes Laërtius (Vitae Philosophorum 7, 74) also says which the criteria that the causal assertible must fulfill are. As indicated by Barnes et al., 2008, p.109), a causal assertible has to continue to fulfill (i) and (ii), but, in addition, it also has another condition (iii). That condition is "that if $p$ is the ground/cause for $q, q$ cannot be the ground/cause for p" (Barnes et al. 2008, p.109; italics in text).

Thus, based on the mental models theory, it can be stated that, given that (i) and (ii) apply to the causal assertible too, a causal assertible can only refer to the combination of possibilities $[A]$, since, as explained in the previous section, $[B]$ and $[C]$ are incompatible with (ii). This circumstance clearly shows the difference be-

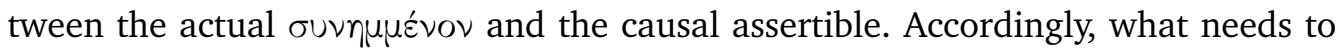
be accounted for now is what the difference between the pseudo-conditional and the causal assertible is.

In my opinion, the key point is that, as noted by Barnes et al., (iii) means that, if 'because $x, y$ ' is true, then 'because $y, x$ ' cannot be true. So, although from the framework of the mental models theory, both the pseudo-conditional and the causal assertible seem to refer to the same combination of possibilities, the semantic relationship between their clauses cannot be the same. This can be easily noted if we ignore for a moment (ii), i.e., the requirement that the antecedent is true. Without (ii), (iii) means that modulation can never eliminate $[B]$ in the case of the causal assertible, that is, as explained, that the causal assertible can never provide a biconditional relationship. And this is so because, if $[B]$ is not possible, that can only mean that situations in which $x$ is false and $y$ is true are not possible, which in turn implies

Principia 20(3): 417-426 (2016). 
not only that if $x$ happens then $y$ happens too, but also that if $y$ occurs then $x$ occurs as well. Obviously, this last consequence is contrary to (iii). Therefore, the relationship between the clauses of the causal assertible must be such that, if the first clause were not true, the second clause could be both true and false.

Nevertheless, the case of the pseudo-conditional is different. Given that it does not need to fulfill (iii), if (ii) is ignored again, its contents can have both semantic relationships forbidding $[B]$ and semantic relationships allowing it. In other words, the biconditional relationship is possible for the pseudo-conditional. So, the Stoic idea appears to be that, when $x$ is true, we can always say 'since $x, y$ '. However, 'because $x, y$ ' is not always enabled. This last expression is only appropriate when we know that $y$ is consistent with both $x$ and $-x$, and that hence 'because $y, x$ ' cannot be stated, even if $x$ and $y$ are both true in that particular time.

But, if this is so, it means that the Stoics were also somehow aware of the problems of the pragmatic phenomenon of the conditional perfection. This phenomenon, as it is well known, refers to the fact that the conditionals can be perfected, that is, interpreted as biconditionals. This is a very studied and researched issue too (just only some works on it can be, e.g., Auwera 1997; Horn 2000; López-Astorga 2014b; Moldovan 2009), and this paper is not intended to address the controversies about it. The only relevant point in this regard for my aims is that requirements such as (iii) show that the discussion on the conditional perfection is not recent, and that it began much earlier than thought, in particular, in ancient times. As said, the Stoics' account in this way was based on the term 'because.' If that word appeared in a sentence, the listener or reader should know that that sentence could not be interpreted in the two directions, and that the first clause was clearly the ground of the cause of the second clause.

All of this can be seen better if some examples are considered. If we retake the previous example and think about the relationship between eating and moving the mouth again, we can say that, according to the Stoic analysis, it is always possible to state that 'if you are eating, you are moving your mouth', since moving the mouth is derived from the fact of eating. Nonetheless, if it were true that you are eating right now, it could also be claimed 'since you are eating, you are moving your mouth'. In addition, because eating cannot be drawn from the fact of moving the mouth (one might move his/her mouth to, for example, sing or speak), it could even be stated 'because you are eating, you are moving your mouth' (provided it were not false that you are eating at the moment of speaking).

However, as accounted for, this is not always so. In the case of, for example, the relationship between being a human being and being a rational being, of course, it can be claimed that 'if you are a human being, you are a rational being'. And, if it were true that the word 'you' refers to a human being, it could also be said that 'since you are a human being, you are a rational being'. What could not ever be stated is 
that 'because you are a human being, you are a rational being'. And the reason of this last impossibility is obvious: it can be stated that if you are a rational being, you are a human being'. Besides, if the term 'you' referred to a rational being, 'since you are a rational being, you are a human being' would be a correct sentence as well.

\section{Conclusions}

Probably, the previous arguments could be further developed taking into account certain theses raised in the literature on the Stoics in general and Stoic logic in particular, such as, for example, that of Barnes et al. (2008, p.108) referring to that both the pseudo-conditional and the causal assertible were studied by the Stoics from the essential framework provided by the Chrysippus' criterion indicated above. I think that my explanations here are coherent with ideas such as this one. However, the point of this paper is not that it offers a better clarification of the conditions that

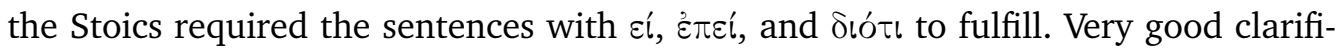
cations and explanations of that are to be found in that very literature. Its point is that it shows that many problems of current cognitive sciences are old problems that ancient philosophers and logicians dealt with and studied.

Hellenistic philosophers already noted that the conditional sentences with 'if' could be interpreted in different ways. Likewise, the Stoics saw that there were sentences that appeared to establish relationships akin to the conditional one, and wanted to identify them and describe what distinguished them from those which were really conditional. In addition, although they did not use that denomination, they faced pragmatic phenomena such as that of the conditional perfection, and thought about the resources that language gives to avoid it.

All of this was made by means of the analysis of certain words that sometimes seem to be synonymous (both in ancient Greek and in other languages such as English) in order to indicate, for each case and semantic relationship between clauses, which of them was the most appropriate. Thus, it is possible that they intended to

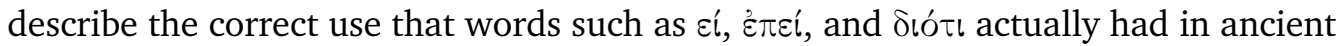
Greek, or the meaning that the Greeks truly gave those terms. Nevertheless, it can also be thought that maybe what they did was just to offer technical definitions with the full intention of finding logical rigor and avoid the confusion that the ordinary use of those words caused. But, be that as it may, what is absolutely true is that, as said, their problems were not very different from ours today, which evidently reveals that a lot of work still has to be done not only in cognitive science, but also in psychology, philosophy of language, linguistics, and any field related to the issues reviewed in this paper.

In any case, another important point is that, if the mental models theory is able

Principia 20(3): 417-426 (2016). 
to help us understand better both Stoic logic and the difficulties linked to the problems analyzed here, perhaps it is worth taking it into account seriously when such problems are studied. Indeed, the semantic analysis of possibilities appears to show clearly what the possible interpretations of the conditional can be, and to what extent a sentence without 'if' can refer to the same models or possibilities as the conditional. Furthermore, this is not the first paper reviewing Stoic logic from the mental models theory perspective. Another paper in this regard can be, as mentioned, for example, that of López-Astorga (2016), which seems to suggest that the possibility to interpret Stoic logic based on the mental models theory reveals that, although prima facie one might think the opposite, maybe the former was a framework more semantic than syntactic (using these concepts in the sense that the mental models theory gives them). So, it appears that it would not be trivial to continue to work in this direction.

\section{References}

Auwera, J. van der. 1997. Pragmatics in the last quarter century: The case of conditional perfection. Journal of Pragmatics 27: 261-274.

Barnes, J.; Bobzien, S.; Mignucci, M. 2008. Logic. In: K. Algra; J. Barnes; J. Mansfeld; M. Schofield (eds.) The Cambridge History of Hellenistic Philosophy, pp.77-225. Cambridge, UK: Cambridge University Press.

Bocheński, I. M. 1963. Ancient Formal Logic. Amsterdam, The Netherlands: North-Holland.

Burnyeat, M. F. 1982. The origins of non-deductive inference. In: J. Barnes; J. Brunschwig; M. Burnyeat; M. Schofield (eds.) Science and Speculation: Studies in Hellenistic Theory and Practice, pp.193-238. Cambridge, UK, and Paris, France: Cambridge University Press and Editions de la Maison des Sciences de l'Homme.

Gentzen, G. 1934. Untersuchungen über das logische Schließen I. Mathematische Zeitschrift 39: $176-210$.

- 1935. Untersuchungen über das logische Schließen II. Mathematische Zeitschrift 39: 405-431.

Gould, J. B. 1970. The Philosophy of Chrysippus. Albany, NY: State University of New York Press.

Horn, L. R. 2000. From if to iff: Conditional perfection as pragmatic strengthening. Journal of Pragmatics 32: 289-326.

Johnson-Laird, P. N. 2006. How We Reason. Oxford, UK: Oxford University Press.

- 2010. Against logical form. Psychologica Belgica 5(3/4): 193-221.

. 2012. Inference with mental models. In: K. J. Holyoak; R. G. Morrison (eds.) The Oxford Handbook of Thinking and Reasoning, pp.134-145. New York, NY: Oxford University Press.

- 2015. How to improve thinking. In: R. Wegerif; L. Li; J. C. Kaufman (eds.) The Routledge International Handbook of Research on Teaching Thinking, pp.80-91. Abingdon, UK, \& New York, NY: Routledge.

Johnson-Laird, P. N.; Byrne, R. M. J. 2002. Conditionals: A theory of meaning, pragmatics, and inference. Psychological Review 109(4): 646-678.

Principia 20(3): 417-426 (2016). 
Johnson-Laird, P. N.; Khemlani, S.; Goodwin, G. P. 2015. Logic, probability, and human reasoning. Trends in Cognitive Sciences 19(4): 201-214.

Khemlani, S.; Orenes, I.; Johnson-Laird, P. N. 2014. The negation of conjunctions, conditionals, and disjunctions. Acta Psychologica 151: 1-7.

López-Astorga, M. 2014a. Mental models and syntactic rules: A study of the relations between semantics and syntax in inferential processes. Analele Universitatii din Craiova 33(1): 107117.

- 2014b. ¿Podemos evitar la perfección del condicional enfocando el antecedente o son necesarios antecedentes alternativos? Revista Signos 47(85): 267-292.

- 2015a. Evolved mechanisms versus underlying conditional relations. Studies in Logic, Grammar and Rhetoric 40(53): 241-253.

2015b. Diodorus Cronus and Philo of Megara: Two accounts of the conditional. Rupkatha 7(3): 9-16.

. 2015c. Chrysippus' indemonstrables and mental logic. Croatian Journal of Philosophy 15(43): 1-15.

- 2016. The first rule of Stoic logic and its relationship with the indemonstrables. Tópicos 50: 9-23.

Mates, B. 1953. Stoic Logic. Berkeley and Los Angeles, CA: University of California Press.

Moldovan, A. 2009. Pragmatic considerations in the interpretation of denying the antecedent. Informal Logic 29(3): 309-326.

Mueller, I. 1978. An introduction to Stoic logic. In: J. M. Rist (ed.) The Stoics, pp.1-26. Berkeley, CA: University of California Press.

O’Toole, R. R.; Jennings, R. E. 2004. The Megarians and the Stoics. In: M. D. Gabbay; J. Woods (eds.) Handbook of the History of Logic, Volume I. Greek, Indian and Arabic Logic, pp.397-522. Amsterdam, The Netherlands: Elsevier.

Miguel LÓPEZ-AstorgA Institute of Humanistic Studies "Juan Ignacio Molina”

University of Talca

Chile

milopez@utalca.cl

Principia 20(3): 417-426 (2016). 